\title{
The Leptin Level in Development of Knee Osteoarthritis Disease
}

\author{
Authors \\ Dr. Mustafa Saleam Khalaf \\ AL-Rasheed University College, Baghdad, Iraq \\ E-mail : dr.mustafa_saleam@alrasheedcol.edu.iq
}

Mobile / +9647725503941

\begin{abstract}
Subject :Knee Osteoarthritis (HOA)is know as degenerative cartilage cell disease in joint association with generation various inflammatory responses. This disease is more common in geriatric and effected by many factors such as obesity . Leptin is hormones secreted of fatty tissue involve as mediators in many pathophysiology process, and support inflammation at cartilage of knee joint .
\end{abstract}

Objective of the Study: Role of leptin concentration level in progression of knee Osteoarthritis .

Materials and Methods: This study was done on 60 patients with KOA disease and 60 healthy persons (control ), the all subjects age within this study were more than 60 years of both genders .After obtained serum , immediately used quantity method (immunoassay) for measured level of leptin concentration .

Results: This study shows elevation of serum leptin concentration level in KOA group compare with healthy control group .

Conclusion: This study confirms that serum leptin concentration level can act as support KOA disease progression .

Keywords: KneeOsteoarthritis, Leptin and Osteoarthritis . 


\section{$\underline{\text { Introduction }}$}

Osteoarthritis (OA) is one of joint disorders that consideras chronic ,associated with age due to changes in physiologic processes at geriatric, OA know as complex disease characterizedegradation of cartilage cells (chondrocytes) that layering end bones in joints, with interaction recognized inflammatory factors (1). The OA disease has many pathologic factors classified into mechanical (that is effect on weightbearing joints ) and non mechanical (that is effect on non weight-bearing joints ), one of the main cause of OA disease is obesity ${ }^{(2)}$.The knee joints consider as the weight-bearing joints .

Adipokines are hormones secreted of fatty tissue involve as mediators in many pathophysiology process (such as rheumatic diseases),newly recognized family of compounds like leptin. The leptin has role in contribute of OA prevalence in obesity persons ${ }^{(3)}$.

Many studies suggested the correlation between OA disease and leptin level in weight-bearing joints like knee joints, but few studies included the correlation with non weight-bearing joints like hand joints . Leptin level consider risk factor to degradation of cartilage cells in joints due to it's has link KOA disease and obesity ${ }^{(4)}$.

The study aim is evaluate leptin level in KOA group and healthy control group at comparison study .

\section{Materials and Methods}

The present study included 60 cases with KOA disease and 60 healthy persons (as control) groups, all individuals age was more 60 years of both sexes. The sampling process of all subjects was random manner ,blood samples separatedimmediately without any preservative factor to product serum as pure form .The serum used for measured leptin concentration level (as quantity measurement )by immunoassay method.

After measurement, used t-test method for statistic analysis to show different of leptin level by comparison between KOA patients and control groups via used mean \pm standard deviation (SD) and p-value (p-value > 0.05 mean significant value ).

\section{Results}

The present study explain a different ofleptain concentration level between KOA patients and healthy control groups via used mean \pm SD statistic method .The leptin level found in KOA group was 12.1 \pm 7.4 ,while in control group was $9.5 \pm 8.8$ with $\mathrm{P}$-value was 0.021 .The present 
result confirms elevation of leptin concentration level in KOA group .Show table 1.

Table 1: Comparison of serum leptin level between KOA and control groups according to mean \pm standard deviation $(S D)$

\begin{tabular}{|c|c|c|c|}
\hline Parameters & $\begin{array}{c}\text { KOA group (No. } \\
=60) \\
\text { Mean+SD }\end{array}$ & $\begin{array}{c}\text { Control group } \\
\text { (No. =60) } \\
\text { Mean+SD }\end{array}$ & P-value \\
\hline $\begin{array}{c}\text { Leptin level } \\
\text { (ng/ml) }\end{array}$ & $12.1 \pm 7.4$ & $9.5 \pm 8.8$ & $0.021^{*}$ \\
\hline
\end{tabular}

*Significant value

\section{Discussion}

The KOA is degenerative cartilage joint disease consider as more prevalence disease in geriatric, and it consider as complex disease due to interact of many pathological factors to generate this disease such as mechanicalfactor, non mechanicalfactor and cytokiens . The cytokines and hormones secreted of fatty tissue like leptin act to support of inflammatory process in joints ${ }^{(3)}$.

There are many studies such as Stannus et al study showed correlation between general OA patients, leptin concentration level and joint pain , this studies showed elevated of leptin level with reduced cartilage thickness that product from cartilage degradation ${ }^{(5)}$.Also there are studies showed correlation between leptin level with KOA at specially form , Ionescu EV et al explained that concluded that leptin is partially involved in the relationship between $\mathrm{BMI}$ and $\mathrm{KOA}^{(6)}$.

The knee joint effect by mechanical factors such as knee joints ,so this study remarkable to focus on involve of mechanical factors on generate of KOA . This study demonstrated elevated of leptin level in KOA , and agree with previous studies. We recommend to other studies and take more KOA patients to confirm this study results .

\section{Conclusion}

This study concluded to confirms that serum leptin concentration level are elevate in KOA cases compare with healthy control , this support that leptin involve in pathological process that product cartilage degradation in knee joints . 


\section{References}

1-Liu-Bryan R, Terkeltaub R. Emerging regulators of the inflammatory process in osteoarthritis. Nature Reviews Rheumatology. 2015 Jan;11(1):35 .

2-Vuolteenaho K, Koskinen A, Moilanen E. Leptin-a link between obesity and osteoarthritis. Applications for prevention and treatment. .Basic \& clinical pharmacology \& toxicology. 2014 Jan;114(1):103-8. 3-Azamar-Llamas D, Hernandez-Molina G, Ramos-Avalos B, FuruzawaCarballeda J. Adipokine contribution to the pathogenesis of osteoarthritis. Mediators of inflammation. 2017 Oct;2017 .

4-Scotece M, Conde J, Gómez R, López V, Lago F, Gómez-Reino JJ, Gualillo O. Beyond fat mass: exploring the role of adipokines in rheumatic diseases. TheScientificWorldJournal. 2011 Jan 1;11.

5-Zhu Z, Otahal P, Wang B, Jin X, Laslett LL, Wluka AE, Antony B, Han W, Wang X, Winzenberg T, Cicuttini F. Cross-sectional and longitudinal associations between serum inflammatory cytokines and knee bone marrow lesions in patients with knee osteoarthritis. Osteoarthritis and cartilage. 2017 Apr 1;25(4):499-505 .

6-Ionescu EV, Oprea C, Almasan ER, Stanciu LE, Iliescu MG. Biological Variation under Balneal Treatment of Serum Level of Leptin in Relation with Body Mass Index in Case of Patients Suffering from Knee Osteoarthritis. Journal of Environmental Protection and Ecology. 2017 Jan 1;18(1):375-85. 